\title{
The current state of orthopaedic residency in 18 European countries
}

\section{Madanat, Rami}

2017-04

Madanat , R, Makinen , T J , Ryan , D , Huri , G , Paschos , N , Vide , J \& FORTE Writing

Comm 2017 , ' The current state of orthopaedic residency in 18 European countries ' , International Orthopaedics, vol. 41 , no. 4 , pp. 681-687 . https://doi.org/10.1007/s00264-017-3427-0

http://hdl.handle.net/10138/236755

https://doi.org/10.1007/s00264-017-3427-0

publishedVersion

Downloaded from Helda, University of Helsinki institutional repository.

This is an electronic reprint of the original article.

This reprint may differ from the original in pagination and typographic detail.

Please cite the original version. 


\title{
The current state of orthopaedic residency in 18 European countries
}

\author{
Rami Madanat ${ }^{1}$ - Tatu J. Mäkinen ${ }^{1} \cdot$ Daniel Ryan $^{2} \cdot$ Gazi Huri $^{3} \cdot$ Nikolaos Paschos $^{4}$. \\ Joao Vide ${ }^{5,6} \cdot$ and the FORTE writing committee
}

Received: 7 January 2017 / Accepted: 5 February 2017 /Published online: 16 February 2017

(C) SICOT aisbl 2017

\begin{abstract}
Purpose The aim of this study was to compare differences in current orthopaedic and trauma training programs across Europe.

Methods A questionnaire was sent to the FORTE (Federation of Orthopaedic Trainees in Europe) representatives of 25 different European countries, of which 18 responded. The questionnaire included demographic information and information concerning the structure of the training programs, including duration, selection, and mandatory training requirements.

Results The number of trainees per specialist varied between countries from a ratio of 1:2 to 1:7. Residency was generally
\end{abstract}

FORTE writing committee: Stjepan Dokuzovic, Croatia; Bjarke Viberg, Denmark; Charles Riviere, France; Matthias Klotz, Germany; Fiachra Rowan, Ireland; Bujar Shabani, Kosovo; Kurstein Sant, Malta; Kjartan Koi, Norway; Yousef Naser, Slovakia; Anže Mihelič, Slovenia; Eduardo Gardella, Spain; Yosef Tyson and Marie Leksell, Sweden; Jasmin Diallo, Switzerland.

Rami Madanat

rami.madanat@hus.fi

1 Department of Orthopaedics and Traumatology, University of Helsinki and Helsinki University Hospital, Sairaalakatu 1, Vantaa PL 900, 00029 HUS Helsinki, Finland

2 Department of Trauma and Orthopaedic Surgery, Gloucestershire Royal Hospital, Great Western Road, Gloucester, UK GL50 3BW

3 Orthopaedics and Traumatology Department, Hacettepe University School of Medicine, 06320 Ankara, Turkey

4 Department of Orthopaedics \& Sports Medicine, Pennsylvania Hospital of the University of Pennsylvania, 800 Spruce Street, Philadelphia, PA 19107, USA

5 Orthopaedics and Traumatology Department, Hospital Beatriz Angelo, Lisbon, Portugal

6 Hospital Particular do Algarve, Faro, Portugal five to six years in all the countries. In more than half of the countries selection was interview-based. Nearly all countries utilized a logbook. About $80 \%$ of the participating countries had a final examination. When assessing the components of training it was found that only one country (the United Kingdom) had mandatory minimum requirements for (1) courses, (2) surgical procedures, (3) research and (4) leadership. Nearly $40 \%$ of the participating countries had only one or none of these four components as a mandatory training requirement.

Conclusions There are many similarities in training programs, but some important differences remain in overall requirements and final qualification. The main limitation of this study was that we were unable to get data from all the European countries. FORTE will continue to serve as a forum for sharing best practices with the ultimate goal of improving and harmonizing the level of orthopaedic training across Europe. Future studies should aim to include further details about training programs as well as to include data from more countries.

Keywords Orthopaedic $\cdot$ Trauma $\cdot$ Residency $\cdot$ Education $\cdot$ Europe

\section{Introduction}

The evolving paradigm of orthopaedic and trauma training is an area that remains frequently discussed among institutions responsible for orthopaedic education. The European Union of Medical Specialists (UEMS) was founded in Brussels in 1958 by the representative delegates of the professional organizations of medical specialists of the six member countries of the European Economic Community (EEC) [1]. The main objectives of UEMS were to establish a high quality and comparable level of medical specialist training in the EU. The 
section of Orthopaedics and Traumatology was founded in 1962 shortly after the initiative of UEMS in order to establish specialist sections.

As in other sections of UEMS, a European Board of Orthopaedics and Traumatology (EBOT) was established in 1994, and the first undertaking was to organize a board examination. The EBOT fellowship examination has been designed to standardize and improve the standard of orthopaedic training in Europe [2]. Although the high quality of the diploma of the EBOT examination has been achieved by a very broad base of support and cooperation of all orthopaedic associations of the UEMS countries, it is still not a mandatory requirement in Europe. Nevertheless, within the EU, the specialist qualification of orthopaedic surgery is automatically recognized (Directive 2005/36/EC on recognition of professional qualifications) in several countries. Furthermore, even if the qualification does not meet the automatic criteria for recognition, it may still be recognised in another EU country, under the general system for recognition of qualifications [3]. Nonetheless, little is known about the similarities and differences in orthopaedic and trauma training programs in European countries, as this information is, in general, not readily available.

Since its inception, The Federation of Orthopaedic Trainees in Europe (FORTE) has aimed to promote and improve the standards of orthopaedic and trauma training in Europe. FORTE also attempts to harmonize orthopaedic training among European countries. This objective is becoming increasingly important with recent developments in the medical profession that introduced a great amount of movement of medical graduates across Europe [4]. For orthopaedic surgery and trauma training, harmonization may be extremely important as training involves knowledge but also practical skills [5]. A descriptive study, which included 857 trainees survey data, has highlighted the importance of several key factors for orthopaedics education such as the development of training programs and increasing the time spent with faculty as well as spreading and promotion of logbook application [6].

In 2015, at the first FORTE summit held in Geneva, national representatives from several European countries met and shared current requirements for residency in their respective countries. Although there were similarities in the residency programs, there were also significant differences as well as several issues acknowledged to be problematic or needing improvement.

The aim of this study was to compare current orthopaedic and trauma training programs across Europe and to understand the main similarities and possible differences.

\section{Materials and methods}

A questionnaire was sent by email to the FORTE representatives of national trainee societies of 25 European countries in September 2015, with reminders sent in October and December of the same year for non-responders. The questionnaire included demographic information regarding the number and gender distribution of trainees and specialists in 2014 . The survey also inquired if there was a national association for trainees and, if so, was it dependent on the national orthopaedic association. The remainder of the questionnaire was related to the structure of the respective orthopaedic training programs and included the following information with emphasis on mandatory requirements: selection process, duration, course training, number of surgical procedures, research, leadership training, examinations, fellowship, and use of a training logbook. The information obtained from the different countries was then compared.

\section{Results}

Representatives from 18 countries (Croatia, Denmark, Finland, France, Germany, Greece, Ireland, Kosovo, Malta, Norway, Portugal, Slovakia, Slovenia, Spain, Sweden, Switzerland, Turkey, and the United Kingdom) answered the questionnaire. The demographic data from the different countries is presented in Table 1 and the information regarding the structure of the residency program in Table 2.

Orthopaedic surgeon densities (number of surgeons per 100,000 population) varied substantially among the participating countries (Fig. 1a). The highest densities were in the Nordic countries with nearly 20 orthopaedic surgeons per 100,000 population. More than half of the participating countries only had densities of only two to six orthopaedic specialists per 100,000 population. The number of trainees per orthopaedic surgeon was calculated in order to understand differences in surgeon replacement rates. This ratio varied between countries from a ratio of 1:2 to 1:7, with no clear geographic patterns within Europe (Fig. 1b). The highest replacement rates were in Finland, Switzerland, Spain and Ireland and the lowest in France, Sweden, and Denmark. The proportion of female trainees was higher (mean 20\%) than the proportion of female orthopaedic specialists (mean 9\%) in nearly all the countries (Fig. 2).

The selection process for entering a residency program varied widely. In more than half of the participating countries selection was based on an interview or a combination of merit and interview. In the remainder, selection was based on the results of a national exam or a simple application process (Fig. 3). The residency program was generally five to six years in all the countries. Nearly all countries utilized a mandatory logbook throughout residency but only a few countries 
Table 1 Demographic data on the number of orthopaedic surgeons and trainees in 18 European countries in 2014

\begin{tabular}{lllll}
\hline Country & $\begin{array}{l}\text { Number of } \\
\text { orthopaedic }\end{array}$ & $\begin{array}{l}\text { Number of } \\
\text { orthopaedic }\end{array}$ & $\begin{array}{l}\text { Number of } \\
\text { orthopaedic }\end{array}$ & $\begin{array}{l}\text { Number of } \\
\text { orthopaedic } \\
\text { surgeons }\end{array}$ \\
$\begin{array}{ll}\text { surgeons } / 100,000 \\
\text { trainees }\end{array}$ & $\begin{array}{l}\text { trainees } / 100,000 \\
\text { population }\end{array}$ & population
\end{tabular}

Is there a national association for trainees?

Dependent on national orthopaedic association?

\begin{tabular}{llllll}
\hline Croatia & $218(6.8 \%)$ & 5.0 & $55(11 \%)$ & 1.3 & Yes, dependent \\
Denmark & $1057(16 \%)$ & 18.9 & $164(29 \%)$ & 2.9 & Yes, independent \\
Finland & $488(14 \%)$ & 9.0 & $248(13 \%)$ & 4.6 & No \\
France & $3157(5 \%)$ & 5.0 & $450(15 \%)$ & 0.8 & Yes, dependent \\
Germany & NA & NA & $500^{\mathrm{a}}(\mathrm{NA})$ & $\mathrm{NA}$ & Yes, dependent \\
Greece & $1819(9 \%)$ & 14.2 & $562(15 \%)$ & 4.4 & Yes, dependent \\
Ireland & $84(0.9 \%)$ & 1.8 & $39(13 \%)$ & 0.9 & Yes, independent \\
Kosovo & $75(1.3 \%)$ & 3.8 & $19(11 \%)$ & 0.9 & No \\
Malta & $19(6 \%)$ & 3.2 & $7(14 \%)$ & 1.4 & No \\
Norway & $975(17 \%)$ & 18.5 & $375(\mathrm{NA})$ & 7.5 & Yes, dependent \\
Portugal & $1005(10 \%)$ & 9.0 & $262(27 \%)$ & 2.5 & Yes, dependent \\
Slovakia & $550(\mathrm{NA})$ & 10.0 & $97(\mathrm{NA})$ & 1.7 & Yes, dependent \\
Slovenia & $90(3 \%)$ & 4.5 & $22(13 \%)$ & 1.1 & No \\
Spain & $2350(29 \%)$ & 15.0 & $1125(41 \%)$ & 2.4 & Yes, dependent \\
Sweden & 1874 & 19.5 & $286(33 \%)^{\mathrm{b}}$ & 2.9 & Yes, independent \\
Switzerland & $889(7 \%)$ & 11.0 & $442(\mathrm{NA})$ & 5.5 & Yes, dependent \\
Turkey & $3117(\mathrm{NA})$ & 4.0 & $976(\mathrm{NA})$ & 1.2 & Yes \\
United & $5071(4.2 \%)$ & 8.0 & $976(19 \%)$ & 1.6 & \\
$\quad$ Kingdo- & & & & & \\
m & & & & & \\
\hline
\end{tabular}

NA data not available

${ }^{\text {a }}$ Approximate number

${ }^{\mathrm{b}}$ Number of orthopaedic trainees who are members of the national organization. Membership is not mandatory utilized a web-based logbook (Ireland, Malta, Slovenia, the United Kingdom). There were still a small number of countries (France, Norway, Sweden) that did not require a logbook for keeping track of residents' achievements (Fig. 3).

Nearly $80 \%$ of the participating countries had a final examination at completion of residency but the remainder only had some form of interim exams without a mandatory final examination (Fig. 4). Most of the participating countries did not have a mandatory fellowship requirement. When assessing the components of training it was found that only one country (the United Kingdom) had mandatory minimum requirements for (1) courses, (2) surgical procedures, (3) research and (4) leadership. Surprisingly, nearly $40 \%$ of the participating countries had only one or none of these four training components as a mandatory part of residency requirements (Fig. 4). For the countries that had minimum requirements for course training and surgical procedures, these requirements varied from $50-360$ hours and $300-1800$ procedures, respectively. Research and leadership training were only a mandatory part of orthopaedic training programs in $40 \%$ of the countries (Fig. 5). Finally, nearly $70 \%$ of the countries had an association for orthopaedic residents. Most of these associations were dependent on the national orthopaedic association.

\section{Discussion}

The aim of this study was to collect demographic and structural data regarding current orthopaedic and trauma training programs across Europe and make comparisons between them. We found that while there are many similarities across residency programs, some important differences still remain in overall requirements and final qualification.

There were clear differences in both orthopaedic surgeon densities and replacement rates across Europe, reflecting possible inherent disparities in both the structure of the healthcare systems as well as in the future need for orthopaedic specialists. The larger proportion of female trainees compared to specialists would indicate a shift in gender parity in the near future. This may be particularly important as orthopaedic surgery has among the lowest percentages of women in residency 


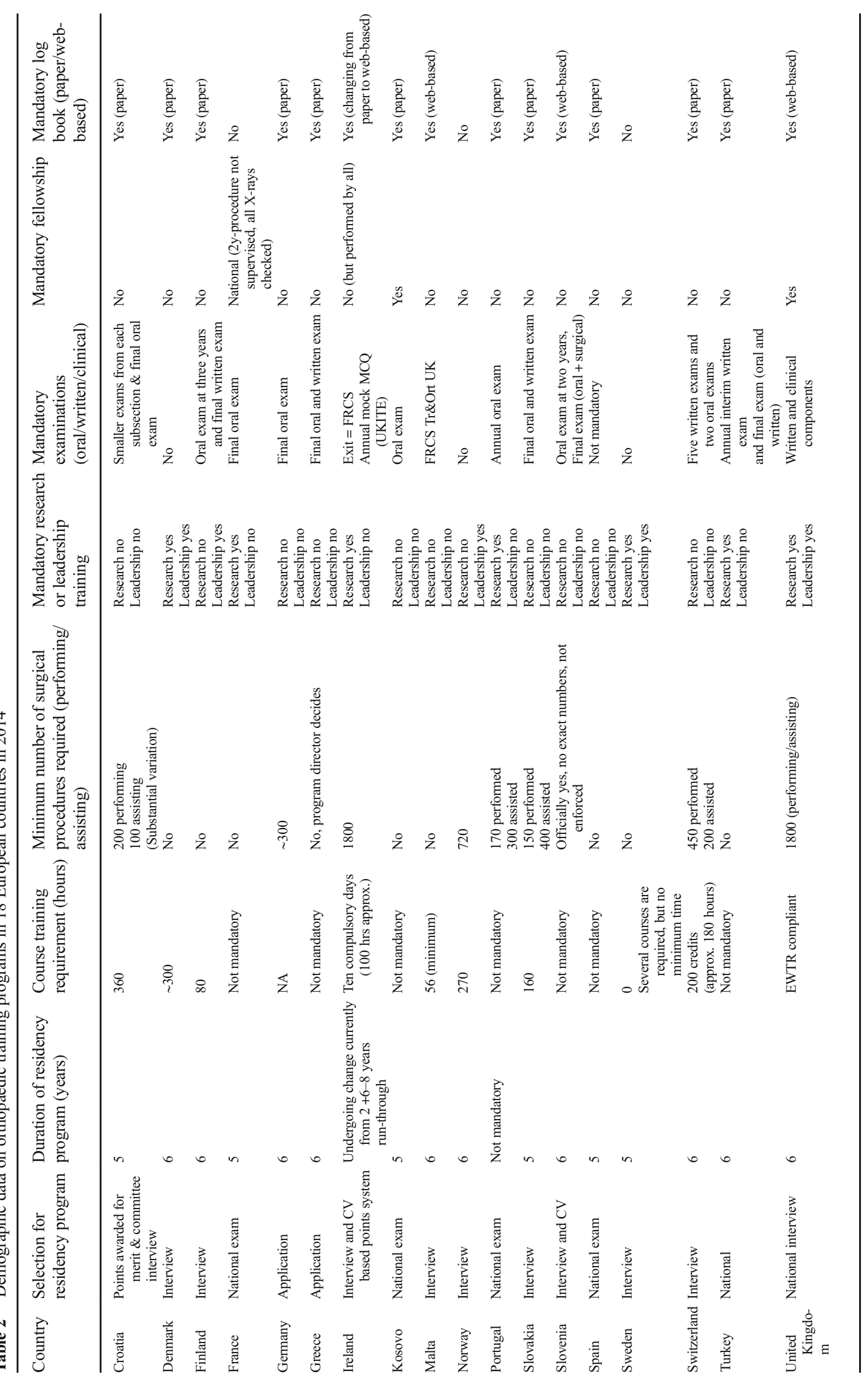


Fig. 1 a Orthopaedic surgeon densities (number of specialists/ 100,000 population) for the different European countries in 2014. b Orthopaedic surgeon replacement rates (the number of trainees per orthopaedic specialist) for the different European countries in 2014 a
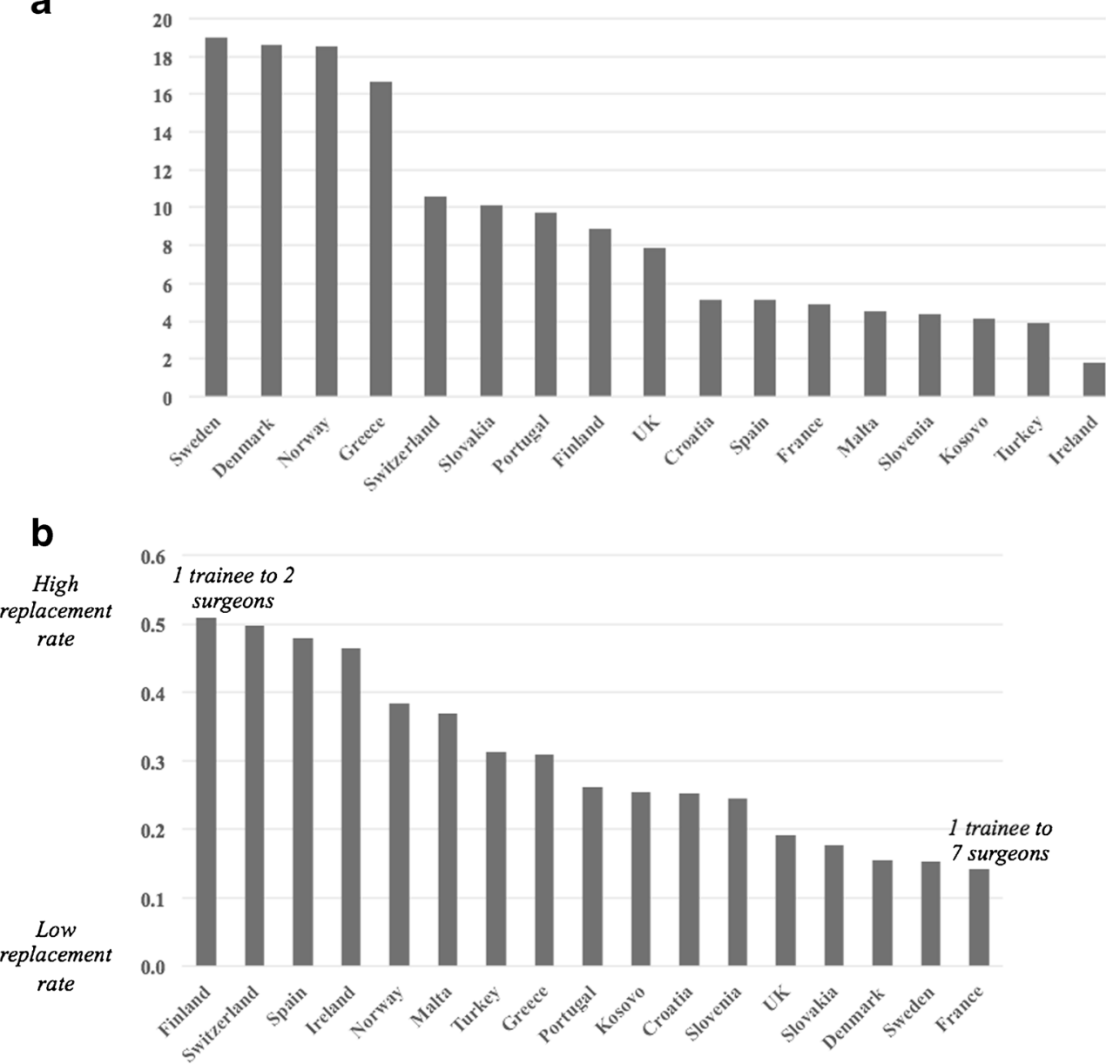

programs of any surgical specialty [7]. The selection process to enter a training program was based on an interview in most countries. In a few countries selection was based on performance in a national examination. One could argue that some form of summative assessment might be beneficial in selecting appropriate candidates for residency. The training program duration in all the countries ranged from five to six years meeting the minimum EU requirements for orthopaedic specialist training. Nearly all countries utilized a logbook for tracking the performance of residents and there was a tendency for the logbook to be moving from a paper version towards a web-based form. Some countries still did not have a
Fig. 2 Proportion of female orthopaedic trainees and specialists for the different European countries in 2014

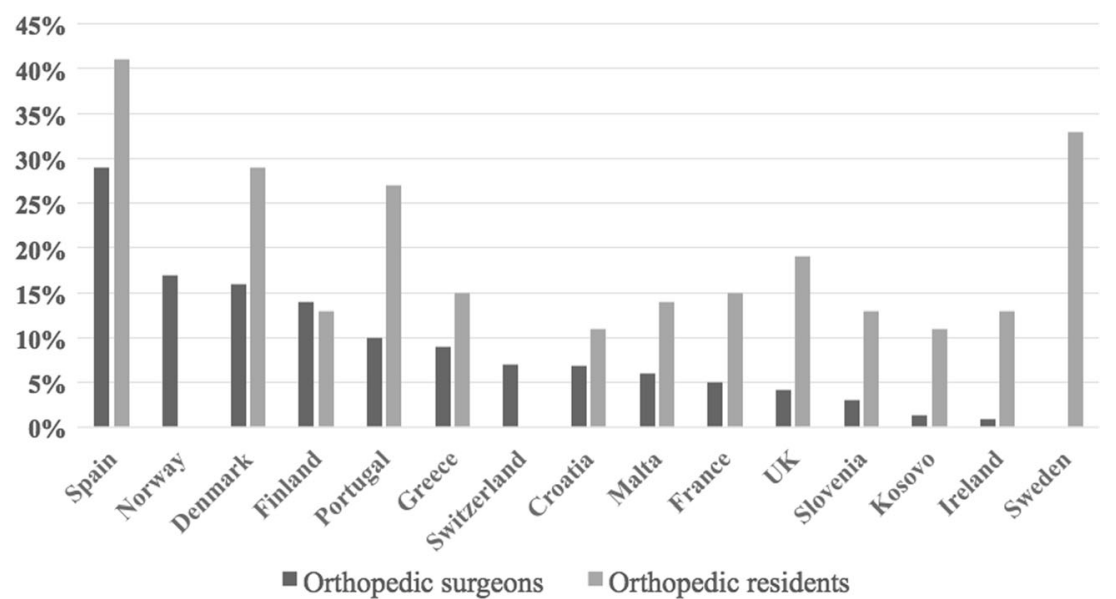


Share of countries
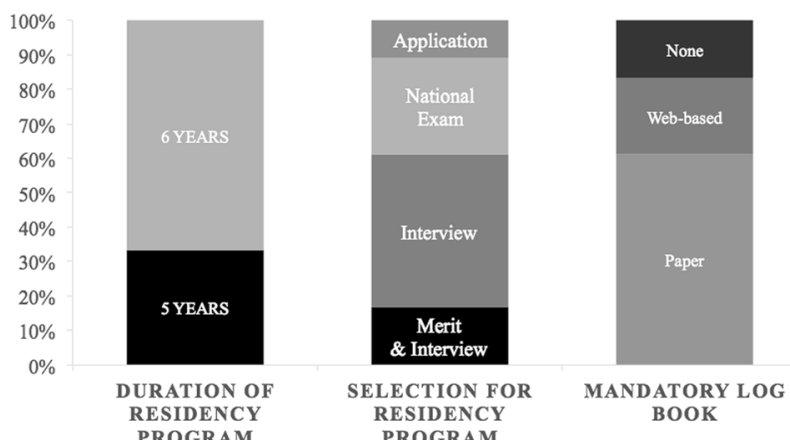

Fig. 3 Duration, selection process and log book requirement for residency programs in the different European countries

mandatory logbook and we believe this is an important issue that can be easily addressed.

Most countries had a final exam but there were still a few that had no form of final examination. In such countries the EBOT exam could serve as a potential final assessment of competency. For the purposes of the present study, we divided the key mandatory components of training into four categories: course training, surgical procedures, research, and leadership. Most would agree that the first two are essential components of training, whereas the latter two could be considered more elective in nature. Only one country (the United Kingdom) had all four of the aforementioned components of training as mandatory. Nearly half of the countries did not have a minimum number of mandatory surgical procedures or course training requirements. For the remainder that did, there was a substantial variation in the minimum requirements. We believe there is definitely room for improvement in both of these aspects. A recent study by LaPorte et al. aimed to determine the best way to assess the operating skills of would-be orthopaedic surgeons [8]. They argued that traditional measures for assessing skills such as logbooks tend to assess volume but not level of surgical proficiency. They found that tracking the trainees' performance on cadavers using step-by-step checklists and measures of general skills

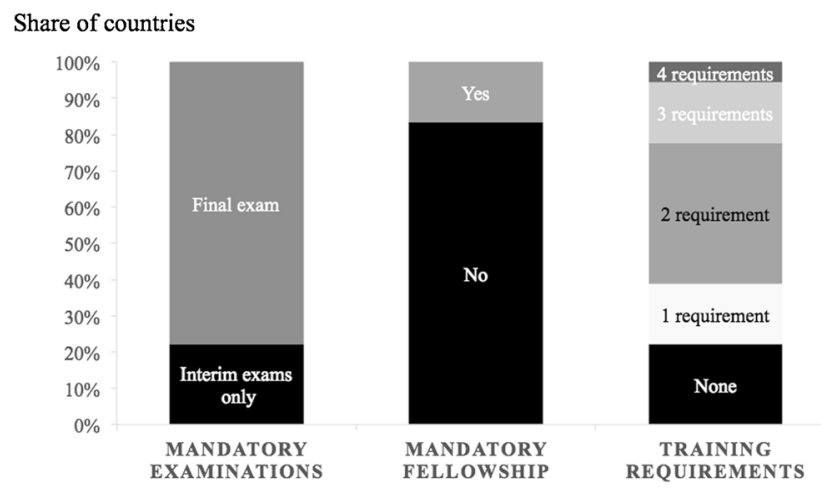

Fig. 4 Mandatory examinations, fellowship, and training requirements (courses, surgical procedures, research, and leadership) for residency programs in the different European countries
Share of countries

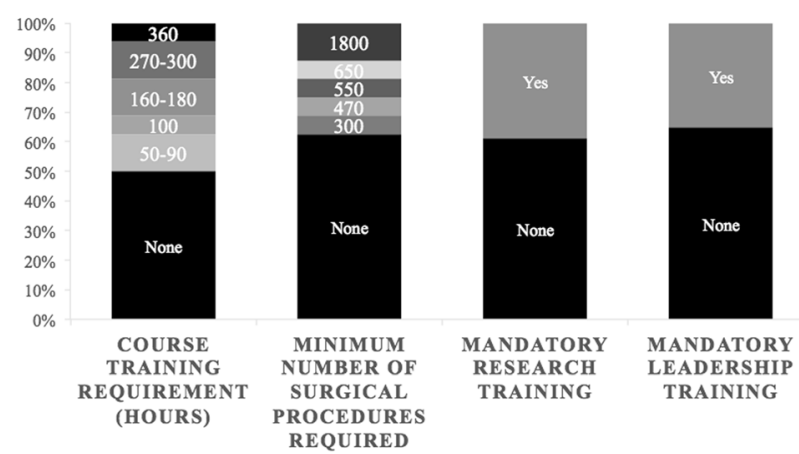

Fig. 5 Minimum requirements for four main areas of training (courses, surgical procedures, research, and leadership) for residency programs in the different European countries

works well but should be coupled with an equally rigorous system for tracking errors [8]. Another recent study examined the implementation of a month long, low-cost, comprehensive surgical skills curriculum built to address the needs of firstyear orthopaedic trainees without sacrificing clinical experience or burdening inpatient services with trainee absence [9]. The authors found that the program received high satisfaction from both trainees as well as faculty. The program was also found to foster early working relationships between trainees and faculty, which was an unforeseen benefit [9]. Such innovation with both training and assessments will be valuable in further strengthening the various orthopaedic training programs in Europe.

Based on the results of the present study we believe a modern European orthopaedic curriculum should include: (1) a minimum required number of essential surgical procedures that need to be mastered, (2) a minimum mandatory number of hours of course training, and (3) a final comprehensive examination that assesses the trainee's knowledge at the end of training. We also believe that a mandatory log-book, preferably webbased, is an efficient way to track progress and performance throughout training. Leadership training, research projects, and fellowships are also valuable and could be included as an elective addition to the training programs.

The present study had some limitations. We were only able to get data from 18 of 25 countries even though several reminders were sent to non-responders. Furthermore, some of the provided data from the 18 countries was unfortunately lacking due to difficulties in getting reliable information. For these two aforementioned reasons we cannot make definitive statements about the level of orthopaedic and trauma training in Europe as a whole. Another limitation is that we did not include more granular information regarding the detailed structure of the residency programs such as the required rotations through subspecialties or on-call 
requirements as this was outside the scope of the present study. To our knowledge this is the first study that has collected essential information regarding similarities and differences in orthopaedic training programs in numerous European countries. Only by sharing such valuable information can we aim to improve orthopaedic training for future generations not only in Europe but around the world. Future studies should aim at including information from more countries globally.

The labour movement across Europe has become more widespread. However, concerns have been raised regarding the level of knowledge and professional competence of surgeons who have qualified in one country and move to practice in another [1]. It is clear that not only are there differences in training programs between countries, but there may also be considerable variation in training systems and assessments within larger European countries [10]. Furthermore, the scope of the specialty is variable, with some countries distinctly separating orthopaedics and traumatology and varying levels of non-operative and operative management training. The launch of the European educational platform (EEP) in 2012 and the recent work on a European curriculum by UEMS and EFORT are meant to act as a guide for all national associations [1]. It is up to each national association to adopt it or modify it based on national requirements.

In addition to the European curriculum, FORTE has been actively involved in multiple endeavours aimed at improving and harmonizing the level of orthopaedic training across Europe. Some of these projects include a book series for trainees and an orthopaedic summer school, to name a few. FORTE will continue to serve as a forum for sharing best practices with the ultimate goal of building competencies essential for the twenty-first-century orthopaedic surgeon in Europe.

Acknowledgements We would like to thank FORTE secretary Ms. Clara Alves for her help with the study.

\section{Compliance with ethical standards}

Conflict of interest The authors declare that they have no conflict of interest.

Funding Rami Madanat and Tatu Mäkinen received research support from the Jane and Aatos Erkko foundation.

Ethical approval This article does not contain any studies with human participants or animals performed by any of the authors.

\section{References}

1. European Union of Medical Specialists (2012) http://www.uems. net/

2. Mäkinen TJ, Madanat R, Kallio P, Mineiro J, Kiviranta I (2014) The current state of the fellowship examination of the European board of orthopaedics and traumatology (EBOT). Eur Orthop Traumatol 5: 217-220

3. Costigliola V (2011) Mobility of medical doctors in cross-border healthcare. EPMA J 2:333-339

4. Scharer S, Freitag A (2015) Physicians' exodus: why medical graduates leave Austria or do not work in clinical practice. Wien Klin Wochenschr 127:323-329

5. Pour AE, Bradbury TL, Horst P, Harrast JJ, Erens GA, Roberson JR (2016) Trends in primary and revision knee arthroplasty among orthopaedic surgeons who take the American Board of Orthopaedics part II exam. Int Orthop 40(10):2061-2067

6. Huri G, Cabuk YS, Gursoy S, Akkaya M, Ozkan S, Oztuna V, Aydingoz O, Senkoylu A (2016) Evaluation of the orthopaedics and traumatology resident education in Turkey: a descriptive study. Acta Orthop Traumatol Turc 50(5):567-571. doi:10.3944/AOTT. 2015.15.0327

7. O'connor MI (2016) Medical school experiences shape women students' interest in orthopaedic surgery. Clin Orthop Relat Res 474:1967-1972

8. Bernard JA, Dattilo JR, Srikumaran U, Zikria BA, Jain A, LaPorte DM (2016) Reliability and validity of 3 methods of assessing orthopaedic resident skill in shoulder surgery. J Surg Educ 73(6): 1020-1025. doi:10.1016/j.jsurg.2016.04.023

9. Ford SE, Patt JC, Scannell BP (2016) A comprehensive, highquality orthopaedic intern surgical skills program. J Surg Educ 73:553-558

10. Mauser NS, Michelson JD, Gissel H, Henderson C, Mauffrey C (2016) Work-hour restrictions and orthopaedic resident education: a systematic review. Int Orthop 40:865-873 